\title{
A Review of Solar Water Heater Setup Energy Analysis Using Heat Exchanger
}

\author{
S. ARUNKUMAR ${ }^{1}$, B. GURUPRASAD ${ }^{2}$ \\ ${ }^{1}$ PG SCHOLAR MECHANICAL ENGG ., \\ 2 ASSISTANT PROFESSOR DEPARTMENT OF MECHANICAL ENGG., \\ ${ }^{1,2}$ ACGCET, KARAIKUD 630003, TAMILNADU, INDIA.
}

\begin{abstract}
The main objective is to find out the Energy analysis of the solar water heater. This work and analysis to the study is to understand the amount of energy should be stored from the heat exchanger setup. The large amount of energy has to be wasted and useless. So that these large amount of waste heat energy can be stored from the heat exchanger setup. It will help to reduce the large amount of heat energy can be stored and to utilize the needed work. My review work is to calculate the amount of energy can be wasted and how much amount of energy can be stored from the energy storage setup.
\end{abstract}

Keywords:- Solar Water Heater, Heat Exchanger, Energy Analysis.

\section{INTRODUCTION}

Energy analysis is the traditional method of assessing the way energy is used in an operation involving the physical or chemical processing of materials and the transfer and or conversion of energy. This usually entails performing energy balances, which are based on the FLT, and evaluating energy efficiencies. This balance is employed to determine and reduce waste energy emissions like heat losses and sometimes to enhance waste and heat recovery.

However, an energy balance provides no information on the degradation of energy or resources during a process and does not quantify the usefulness or quality of the various energy and material streams flowing through a system and exiting as products and wastes.

The energy method of analysis overcomes the limitations of the FLT. The concept of energy is based on both the FLT and the SLT. Energy analysis clearly indicates the locations of energy degradation in a process and can therefore lead to improved operation or technology. Energy analysis can also quantify the quality of heat in a waste stream. A main aim of energy analysis is to identify meaningful (energy) efficiencies and the causes and true magnitudes of energy losses.

\section{METHODOLOGY}

The energy storage material has selected from the literature paper work. The energy storage has been analysis from the system.

\section{* Energy Analysis}

$>$ Formulae for Energy Analysis

At the time of charging and discharging of the Thermal energy storage, the input and output energies were calculated using the following equations.

$$
\begin{gathered}
E_{\text {in }}=\boldsymbol{m}^{\circ} \boldsymbol{C}_{w} \int_{0}^{t}\left[T_{\text {in }}-T_{\text {out }}\right\rfloor d t \\
E_{\text {out }}=\boldsymbol{m}^{\circ} \boldsymbol{C}_{w} \int_{0}^{t}\left[T_{\text {out }}-T_{\text {in }}\right\rfloor d t \\
0
\end{gathered}
$$

0

Where,

Ein = Heat absorbed by the material

Eout $=$ Heat gained by the Heat transfer fluid(HTF) from the energy storage material

$\boldsymbol{C}_{\boldsymbol{W}}=$ Specific heat of the HTF

$\boldsymbol{T}_{\text {in }}=$ Inlet temperature of the HTF

$\boldsymbol{T}_{\text {out }}=$ Outlet temperature of the HTF

$$
\eta=\frac{E o u t}{\operatorname{Ein}}
$$

\section{EXPERIMENTAL DESCRIPTION}

The energy storage test kit was design and manufacturing by myself. The test kit was tested at alagappa chettiar government college of engineering and technology, karaikudi. The testing time between morning 10 am to evening 4 pm onwards. 


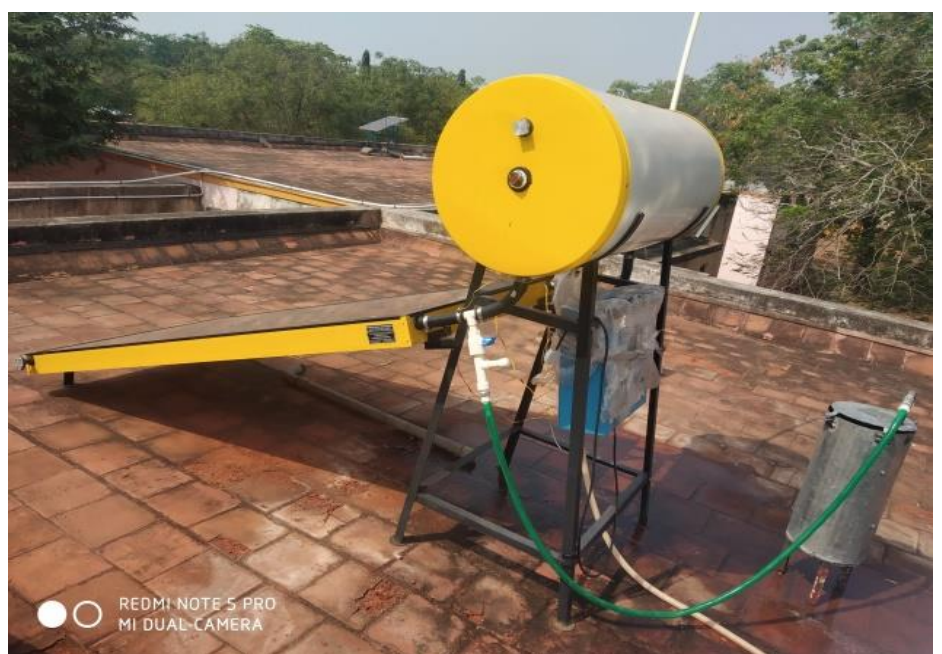

Fig.1:- Energy lab solar water heater connect to the energy storage setup

The test kit was connected to the solar water heater setup at ACGCET college Mechanical department, Energy lab.

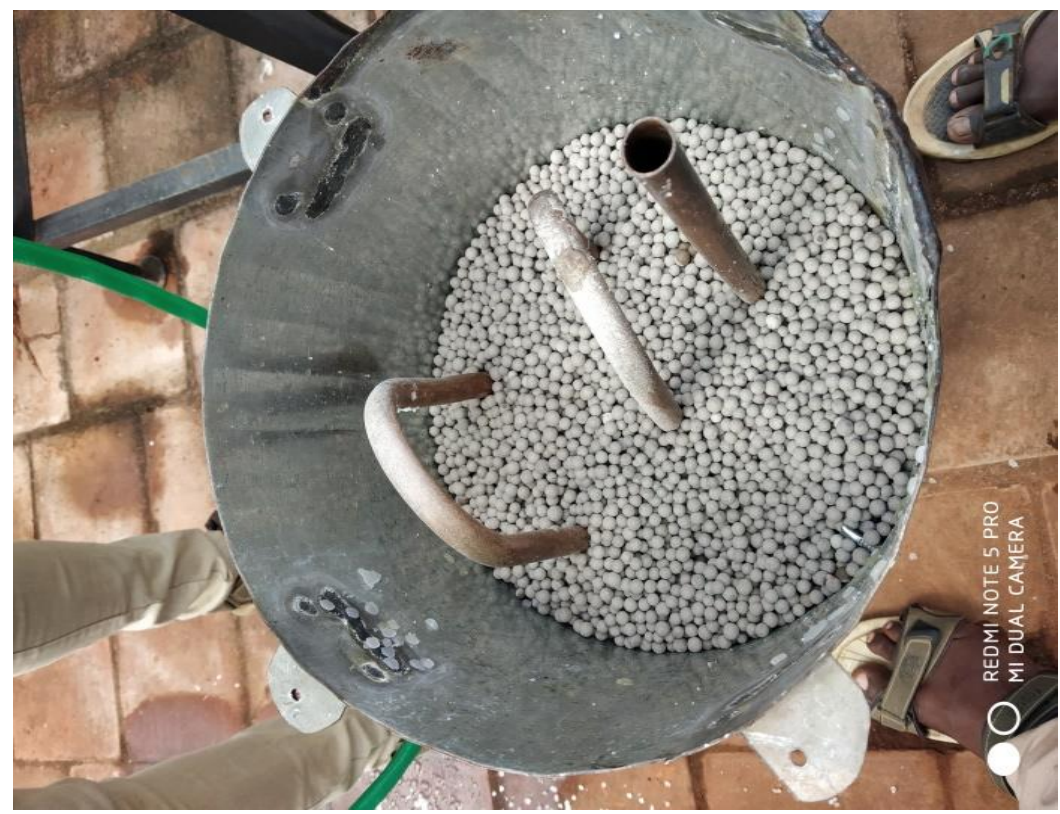

Fig. 2:- Energy storage setup filled with energy storage material(Zeolite)

\begin{tabular}{|c|c|c|c|c|}
\hline Time & Ein(KJ) & Eout(KJ) & Eloss(KJ) & Efficiency (\%) \\
\hline $10 \mathrm{am}$ & 340 & 270 & 60 & 79 \\
\hline $11 \mathrm{am}$ & 325 & 265 & 60 & 81 \\
\hline $12 \mathrm{pm}$ & 300 & 275 & 30 & 81 \\
\hline $1 \mathrm{pm}$ & 285 & 255 & 80 & 71 \\
\hline $2 \mathrm{Pm}$ & 280 & 200 & 85 & 68 \\
\hline $3 \mathrm{Pm}$ & 270 & 185 & 115 & 54 \\
\hline $4 \mathrm{pm}$ & 255 & $140 \quad$ Average efficiency & $76 \%$ \\
\hline
\end{tabular}

Table.1:- Energy analysis 


\section{RESULT AND DISCUSSION}

The experimental work was carried out in two processes, which is mentioned below.

- Energy absorption

- Energy desorption

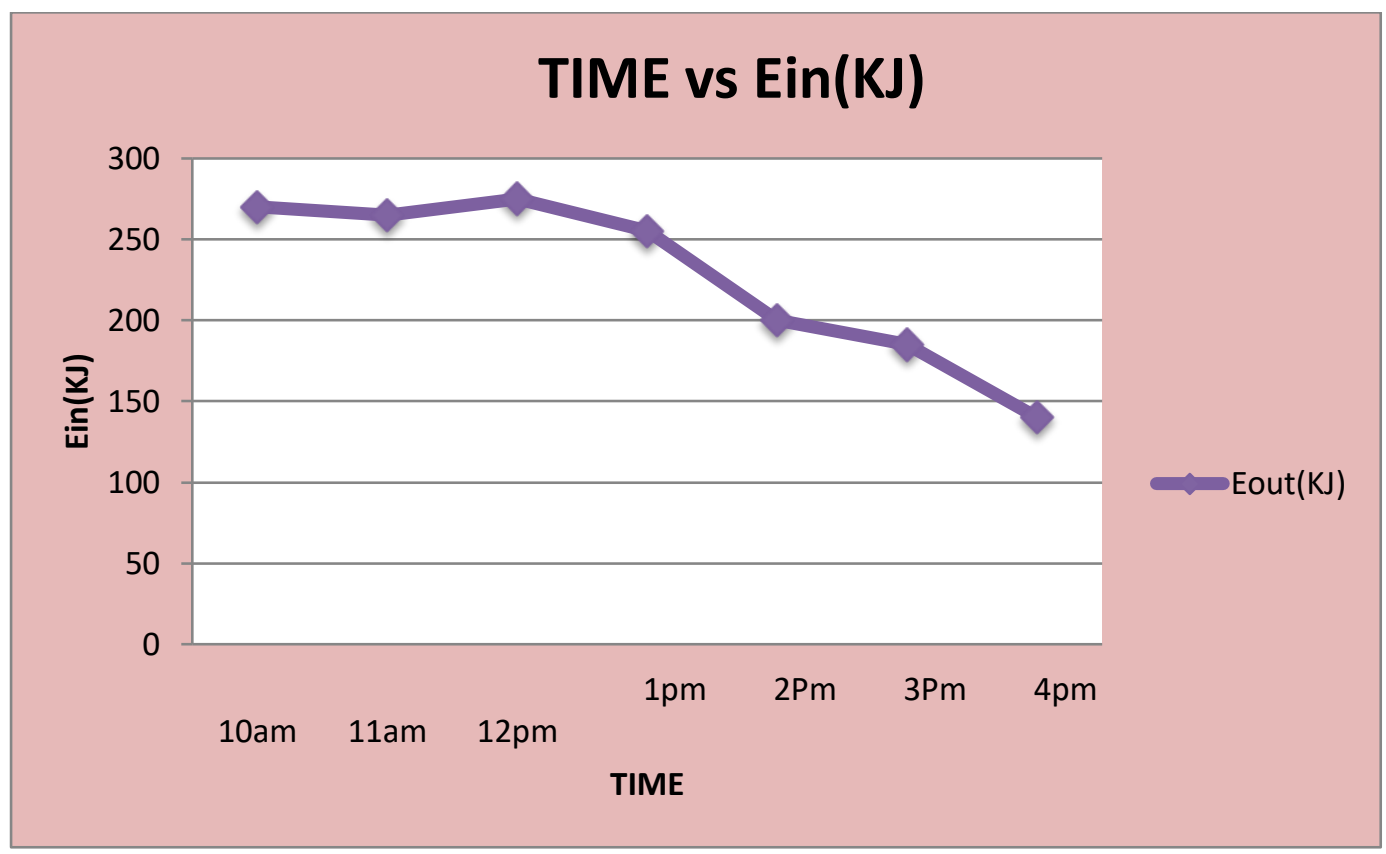

Fig.3:- Energy Absorption Graph

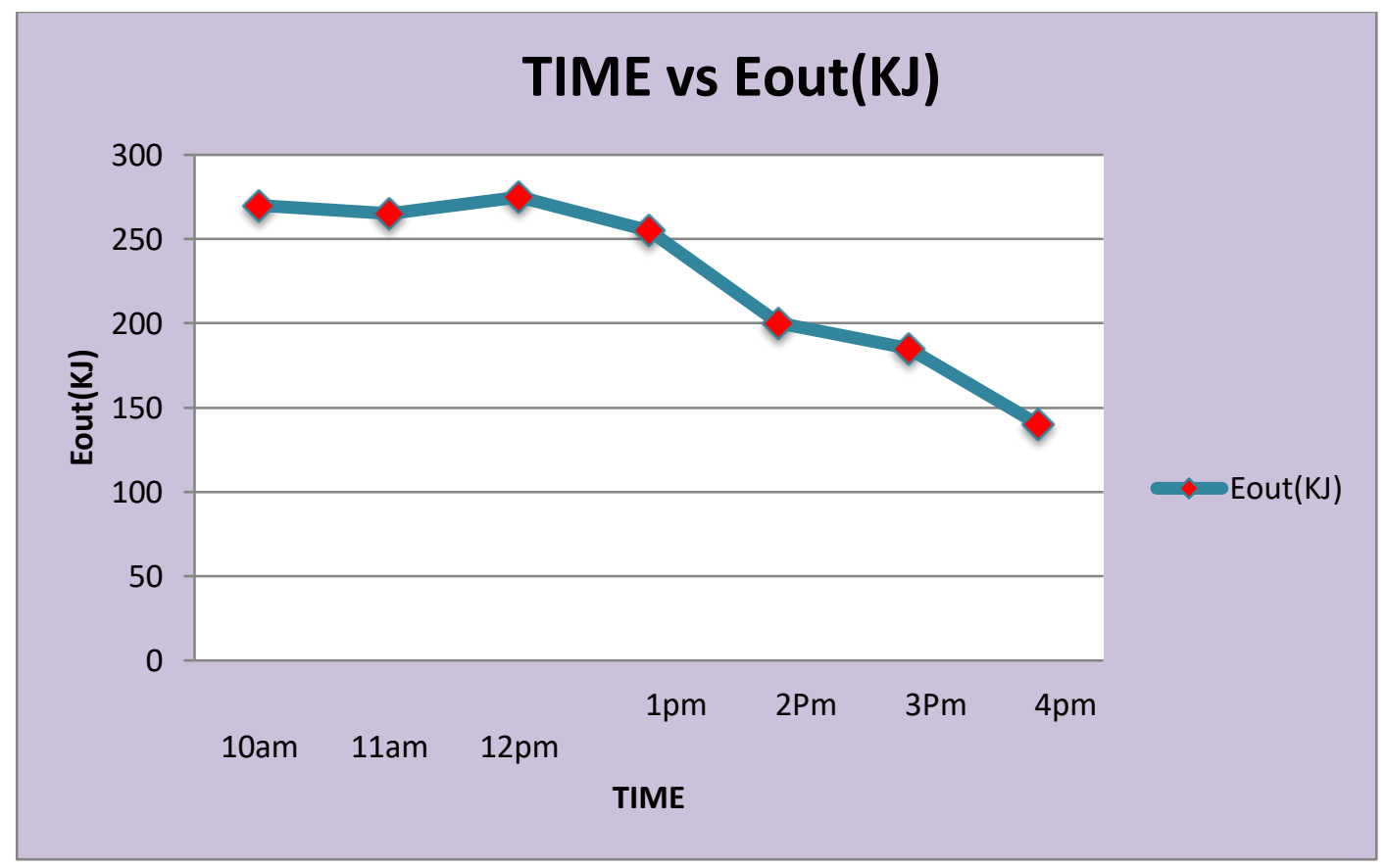

Fig.4:- Energy Desorption Graph 


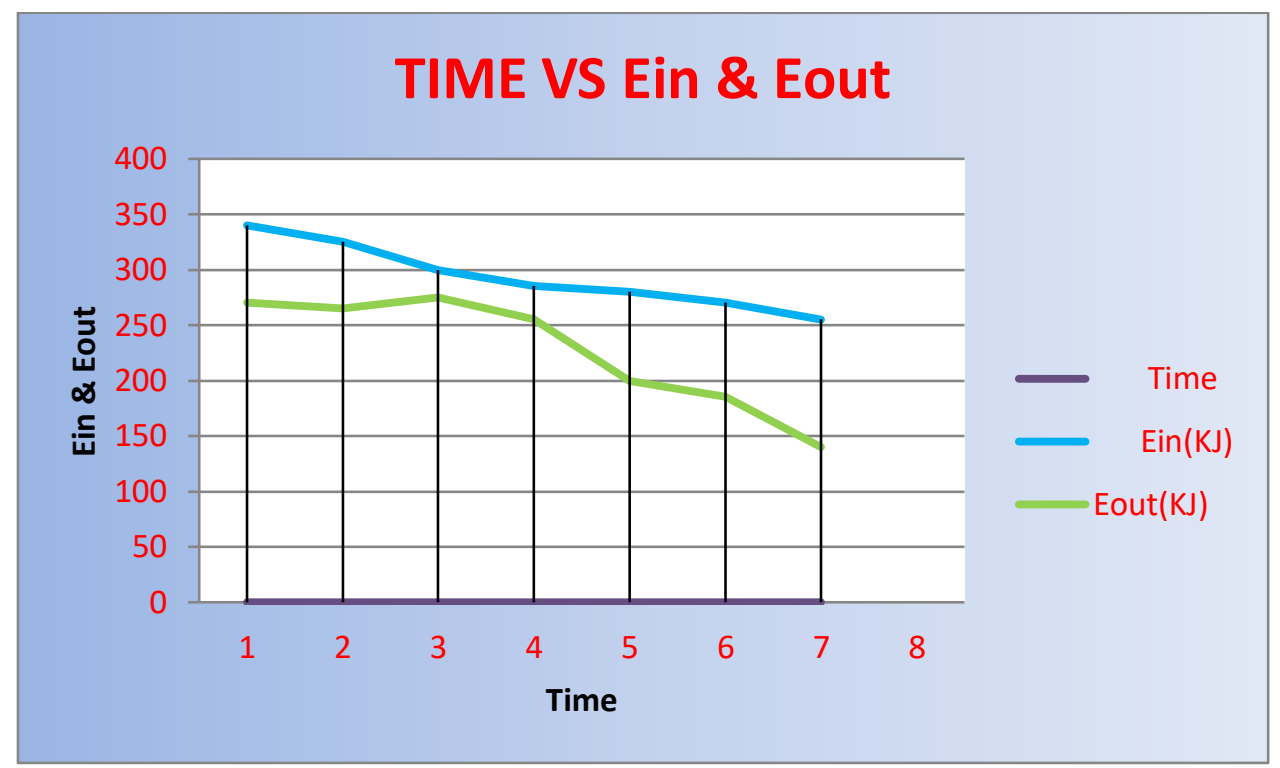

Fig.5:- Time vs Energy in \& Energy out Graph

\section{CONCLUSION}

From the present research work the following concluding remarks are made:

- The experimental setup of shell and tube energy storage device is designed and fabricated, in order to utilize the Energy storage material for solar energy storage and recovery.

- The experimental setup performance was examined by using solar water collector.

- The energy analysis was done and efficiency of the thermal energy storage system was calculated.

\begin{tabular}{|ll|}
\hline \multicolumn{2}{|c|}{ Nomenclature } \\
$\mathrm{A}_{\text {mod }}$ & area of the solar module $\left(\mathrm{m}^{2}\right)$ \\
$\mathrm{C}_{\mathrm{p}}$ & specific heat of air $(\mathrm{kJ} / \mathrm{kg} \mathrm{K})$ \\
$\mathrm{G}$ & solar radiation $\left(\mathrm{W} / \mathrm{m}^{2}\right)$ \\
$\dot{\mathrm{m}}$ & Mass flow rate of water $(\mathrm{kg} / \mathrm{s})$ \\
$\mathrm{Q}_{\mathrm{u}}$ & useful heat $(\mathrm{W})$ \\
$\mathrm{T}_{\mathrm{i}}$ & inlet temperature $\left({ }^{0} \mathrm{C}\right)$ \\
$\mathrm{T}_{\mathrm{o}}$ & outlet temperature $\left({ }^{0} \mathrm{C}\right)$ \\
$\mathrm{v}$ & velocity of water $(\mathrm{m} / \mathrm{s})$ \\
Greek & letters \\
$\rho$ & density $\left(\mathrm{kg} / \mathrm{m}^{3}\right)$ \\
$\eta_{\text {th }}$ & thermal efficiency $(\%)$
\end{tabular}

\section{REFERENCES}

[1]. Vishal G. Shelke1, Chinmay V. Patil2, Kishor R. Sontakke3 "Solar Water Heating Systems: A Review" ,ISSN (Online): 2347-3878, Impact Factor (2014): 3.05

[2]. M. Mani Bharathi, Shams Hari Prasad Mohan, Santhosh Sivan.M, Karthikeyan.S "Design and Fabrication of Shell and Tube Heat Exchanger", ISSN: 2455-7137 Volume 02, Issue - 04, April - 2017, PP - 35-39

[3]. Sandeep Kumar Dehariya*1 Dr. A. R. Jaurker2 “ Efficiency Evaluation of Heat Exchanger Based Domestic Solar Water Heater - A Review", ISSN: 2277-9655

[4]. Shoma Fujiia,*, Naoyuki Horiea, Ko Nakaibayashia, Yuichiro Kanematsub, Yasunori Kikuchib, Takao Nakagakia "Design of zeolite boiler in thermochemical energy storage and transport system utilizing unused heat from sugar mill", applied energy 238(2019) 561-571

[5]. Christoph Lehmanna,b, Steffen Beckertc, Thomas Nonnenc, Jens Möllmerd, Roger Gläserc, Olaf Kolditza,b, Thomas Nagela,e,* Energy Procedia 105 ( 2017 ) $4334-4339$

[6]. 6.Yaxue Lin, Review on thermal conductivity enhancement, thermal properties and Applications of phase change materials in thermal energy storage (2018)

[7]. Energy around the world by $\mathrm{J} \mathrm{C}$ McVeigh, Brighton polytechnic, UK 